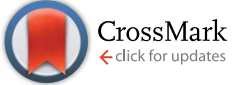

Cite this: Chem. Sci., 2016, 7, 4052

\title{
Catalytic radical reduction in aqueous solution via oxidation of biologically-relevant alcohols $\uparrow$
}

\begin{abstract}
Yamin Htet $^{a}$ and Andrew G. Tennyson*abc
Metalloenzymes that normally perform catalytic antioxidant or radical-degrading functions, as well as small-molecule complexes that mimic them, can also exert pro-oxidant or radical-forming effects depending on the identity of the terminal reductant. Because nitroxyl radicals function as redox active cocatalysts in the aerobic oxidation of alcohols, we hypothesized that catalytic radical reduction could be achieved via the oxidation of biologically-relevant alcohols. Herein we report an organoruthenium complex (Ru1) that catalyzed reduction of 2,2'-azino-bis(3-ethylbenzo-thiazoline-6-sulfonate) radical monoanion $\left(\mathrm{ABTS}^{--}\right.$) to $\mathrm{ABTS}^{2-}$ in phosphate buffered saline $(\mathrm{pH} 7.4)$ using $\mathrm{MeOH}, \mathrm{EtOH}$, i-PrOH, serine, threonine, glucose, arabinose, methyl lactate or dimethyl malate as the terminal reductant. Replacing either the $\mathrm{C}-\mathrm{H}$ or $\mathrm{O}-\mathrm{H}$ groups of a $-\mathrm{CHOH}$ - moiety resulted in the loss of $\mathrm{ABTS}^{\cdot-}$ reducing ability. Moreover, in conjunction with an alcohol terminal reductant, Ru1 was able to inhibit the oxidation of $\mathrm{ABTS}^{2-}$ by $\mathrm{H}_{2} \mathrm{O}_{2}$ and horseradish peroxidase, even after multiple successive challenges with excess $\mathrm{H}_{2} \mathrm{O}_{2}$ or ABTS $^{--}$. Collectively, these results demonstrate that Ru1 inhibits the oxidative formation of and catalyzes the reduction of radicals in aqueous solution via oxidation of biologically-relevant alcohols.
\end{abstract}

Received 12th February 2016 Accepted 4th March 2016

DOI: $10.1039 / \mathrm{c} 6 \mathrm{sc00651e}$

www.rsc.org/chemicalscience which then oxidizes the second equivalent of $\mathrm{H}_{2} \mathrm{O}_{2}$ to $\mathrm{O}_{2}$ and releases $\mathrm{H}_{2} \mathrm{O}^{12}$ At low $\mathrm{H}_{2} \mathrm{O}_{2}$ concentrations, this $\mathrm{Fe}(\mathrm{Iv})=\mathrm{O}^{\cdot+}$ intermediate can abstract $\mathrm{H}^{*}$ from other molecules (i.e., $\mathrm{A}-\mathrm{H}$ ) and thus exhibit peroxidase-like reactivity (Scheme 1-ii). ${ }^{13}$ Conversely, peroxidase can exhibit catalase-like reactivity at low A-H/high $\mathrm{H}_{2} \mathrm{O}_{2}$ concentrations. ${ }^{14}$ Because the Mn-salen and Mn-porphyrin complexes proceed through high-valent Mn oxo/ hydroxo intermediates ${ }^{15-18}$ with oxidizing power comparable to $\mathrm{Fe}(\mathrm{IV})=\mathrm{O}^{\cdot+}$, their reactivity will mimic catalase or peroxidase based on the availability of $\mathrm{H}_{2} \mathrm{O}_{2}$. Therefore, the function of catalase and its biomimetic $\mathrm{Mn}$ complexes as either by catalyzing the disproportionation of $\mathrm{O}_{2}{ }^{-}$and $\mathrm{H}_{2} \mathrm{O}_{2}$, respectively. ${ }^{6}$ Synthetic $\mathrm{Mn}$-salen and $\mathrm{Mn}$-porphyrin complexes have demonstrated both SOD and catalase activity, ${ }^{7}$ and some have entered phase 1 clinical trials as therapeutics for neurodegenerative and pulmonary diseases. ${ }^{8}$

Recent studies have shown that these classes of synthetic Mn complexes can also exert pro-oxidant effects at low ROS concentrations, ${ }^{\mathbf{9}, 10}$ dichotomous behavior that is consistent with the enzymes they mimic. Catalase converts $2 \mathrm{H}_{2} \mathrm{O}_{2}$ into $\mathrm{O}_{2}+$ $2 \mathrm{H}_{2} \mathrm{O}$ (Scheme 1-i), ${ }^{\mathbf{1 1}}$ wherein the first equivalent of $\mathrm{H}_{2} \mathrm{O}_{2}$ is reduced to $\mathrm{H}_{2} \mathrm{O}$ and generates an $\mathrm{Fe}(\mathrm{Iv})=\mathrm{O}^{\cdot+}$ intermediate,

${ }^{a}$ Department of Chemistry, Clemson University, Clemson, SC 29634, USA. E-mail: atennys@clemson.edu

${ }^{b}$ Department of Materials Science and Engineering, Clemson University, Clemson, SC 29634, USA

${ }^{c}$ Center for Optical Materials Science and Engineering Technologies, Anderson, SC 29625, USA

$\uparrow$ Electronic supplementary information (ESI) available. See DOI: 10.1039/c6sc00651e

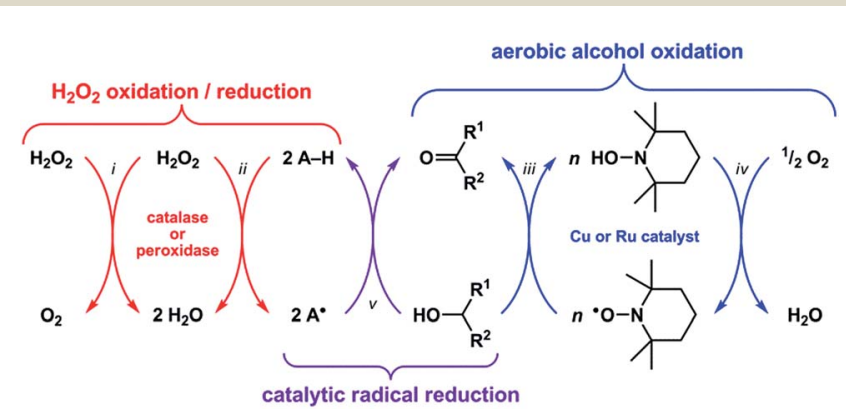

Scheme 1 Catalase normally catalyzes the disproportionation of $\mathrm{H}^{*}$ from other molecules $(\mathrm{A}-\mathrm{H})$ and produce radicals $\left(\mathrm{A}^{*}\right)$ in a manner similar to peroxidase (ii). Copper or ruthenium complexes can catalyze the oxidation of $\mathrm{R}^{1}-\mathrm{CHOH}-\mathrm{R}^{2}$ to $\mathrm{R}^{1}-\mathrm{C}(=\mathrm{O})-\mathrm{R}^{2}$ using a nitroxyl radical (e.g., TEMPO, $n=1$ for $\mathrm{Cu}, n=2$ for $\mathrm{Ru}$ ) as the $\mathrm{H}^{*}$ abstracting reagent (iii) and $\mathrm{O}_{2}$ as the terminal oxidant (iv). By a similar mechanism, a complex could catalyze radical reduction using a biologically relevant non-tertiary alcohol as the terminal reductant (v). $2 \mathrm{H}_{2} \mathrm{O}_{2} \rightarrow \mathrm{O}_{2}+2 \mathrm{H}_{2} \mathrm{O}(\mathrm{i})$, but at low $\mathrm{H}_{2} \mathrm{O}_{2}$ concentrations it can abstract 
antioxidants or pro-oxidants will be determined by the nature of the terminal reductant.

A catalytic oxidation reaction important in synthetic chemistry is the aerobic oxidation of $\mathrm{R}^{1}-\mathrm{CHOH}-\mathrm{R}^{2}$ to $\mathrm{R}^{1}-\mathrm{C}(=\mathrm{O})-\mathrm{R}^{2}$ that does not cause any (1) over-oxidation to $\mathrm{R}-\mathrm{COOH}$ or (2) undesired reactions at other functional groups. ${ }^{19-23}$ One strategy employs a copper or ruthenium catalyst in conjunction with a nitroxyl radical, such as 2,2,6,6-tetramethylpiperidinyl- $N$-oxyl (TEMPO), to oxidize $\mathrm{R}^{1}-\mathrm{CHOH}-\mathrm{R}^{2}$ to $\mathrm{R}^{1}-\mathrm{C}(=\mathrm{O})-\mathrm{R}^{2}$ with concomitant formation of TEMPO-H (Scheme 1-iii). Subsequent regeneration of the TEMPO radical occurs with the oxidation of TEMPO- $\mathrm{H}$ by $\mathrm{O}_{2}$, which functions as the terminal oxidant for this reaction (Scheme 1-iv). Because the TEMPO radical is reduced by $\mathrm{R}^{1}-\mathrm{CHOH}-\mathrm{R}^{2}$ in the aerobic alcohol oxidation catalytic cycle, we hypothesized that the catalytic reduction of other radicals could also be achieved via the oxidation (i.e., dehydrogenation) of non-tertiary alcohols (Scheme 1-v). Herein we report the validation of this hypothesis with an organoruthenium complex that catalyzes the reduction and inhibits the formation of radicals in buffered aqueous solutions via the oxidation of biologically-relevant non-tertiary alcohols. Given the successes of group 8 transfer hydrogenation catalysts as chemotherapeutics ${ }^{24,25}$ in particular and the burgeoning scope of medicinal applications for transition metalbased catalytic systems ${ }^{26-28}$ in general, we anticipate that the reduction of radicals via the Ru-catalyzed oxidation of alcohols will lead to new strategies for protecting against ROS in vivo.

\section{Results and discussion}

\section{Approach and rationale}

We recently reported a Ru complex supported by a chelating N-heterocyclic carbene-carboxylate ligand (Ru1, Scheme 2A) that catalyzed the hydrogenation of $\mathrm{C}=\mathrm{O}, \mathrm{C}=\mathrm{N}$ and $\mathrm{C}=\mathrm{C}$ bonds, in which the $\mathrm{H}_{2}$ transferred was obtained from the oxidation of i-PrOH to acetone..$^{29}$ Based on this catalytic chemical reactivity observed with Ru1 and previous reports of other $\mathrm{Ru}$ complexes with chelating carboxylate ligands exerting antioxidant effects in cells, which derived from irreversible stoichiometric reactions with nitric oxide, ${ }^{30,31}$ we hypothesized that Ru1 would function as a catalytic antioxidant, reducing radicals using non-tertiary alcohols as terminal reductants. Using methods previously reported by our group ${ }^{29,32}$ the N-heterocyclic carbene $(\mathrm{NHC})$ ligand precursor $\left[\mathbf{1 H}_{2}\right][\mathrm{Br}]$ was treated with $\mathrm{Ag}_{2} \mathrm{O}$ to afford the $\mathrm{Ag}-\mathrm{NHC}$ complex $[\mathrm{Ag}(\mathbf{1})]_{n}$ (2). The NHC ligand was subsequently transferred to Ru via the reaction of 2 with $\left[\left\{\mathrm{RuCl}\left(\eta^{6} \text {-cymene }\right)\right\}_{2}(\mu-\mathrm{Cl})_{2}\right]$, which yielded the $\mathrm{Ru}-\mathrm{NHC}$ complex $\left[\operatorname{RuCl}(\mathbf{1})\left(\eta^{6}\right.\right.$-cymene $\left.)\right]$ (Ru1).

As a radical substrate to probe antioxidant activity, 2,2'azino-bis(3-ethylbenzothiazoline-6-sulfonate) radical monoanion $\left(\mathrm{ABTS}^{--}\right.$, Scheme $\left.2 \mathrm{~B}\right)$ was selected on the basis of its large extinction coefficient $(\varepsilon)$ at long wavelengths $\left(\varepsilon_{750}=1.6 \times 10^{4}\right.$ $\mathrm{M}^{-1} \mathrm{~cm}^{-1}$ in EtOH and $\varepsilon_{734}=1.5 \times 10^{4} \mathrm{M}^{-1} \mathrm{~cm}^{-1}$ in aqueous buffer $){ }^{33}$ its reversible one-electron reduction to $\operatorname{ABTS}^{2-}\left(E_{1 / 2}=\right.$ $0.68 \mathrm{~V} v s$. NHE) falling within the range of potentials accessible in biological systems $\left(-0.4\right.$ to $+0.8 \mathrm{~V} v s$. NHE) ${ }^{34}$ and its stability in aerobic, protic media. The longer absorption wavelength and

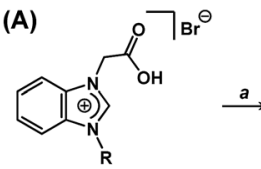

$\left[1 \mathrm{H}_{2}\right][\mathrm{Br}]$

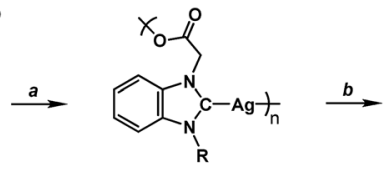

2

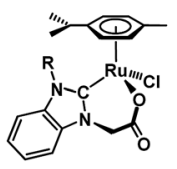

Ru1

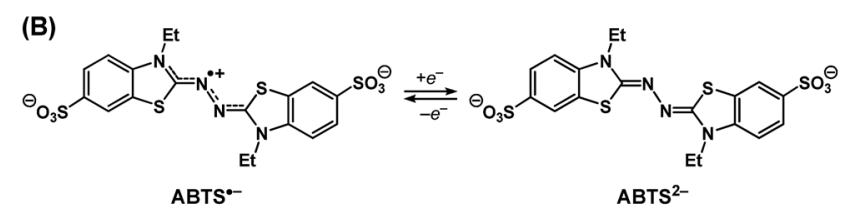

(C)

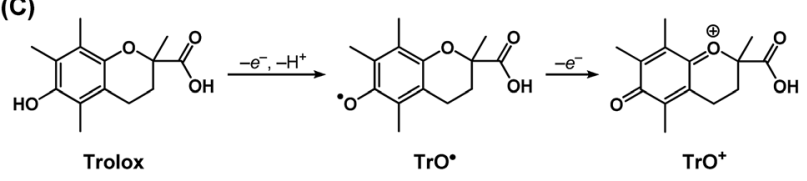

Scheme 2 (A) Synthesis of $\left[1 \mathrm{H}_{2}\right][\mathrm{Br}], 2$ and Ru1. Reagents and conditions: (a) $\mathrm{Ag}_{2} \mathrm{O}$ (1.5 equiv.) or (b) [\{RuCl( $\eta^{6}$-cymene) $\}_{2}\left(\mu-\mathrm{Cl}_{2}\right](1: 1 \mathrm{Ag} /$ $\mathrm{Ru}$ ), $\mathrm{CH}_{2} \mathrm{Cl}_{2}$, room temperature, $24 \mathrm{~h}$. $\mathrm{R}=p$-tolyl. (B) One-electron redox interconversion between $\mathrm{ABTS}^{\circ}{ }^{-}$and $\mathrm{ABTS}^{2-}\left(\mathrm{NH}_{4}{ }^{+}\right.$counterions omitted for clarity). (C) First and second one-electron oxidations of Trolox.

greater extinction coefficient for ABTS ${ }^{--}$enables spectroscopic analysis of radical-degrading and -forming reactions (1) with less interference from other optically absorbing species present in biological systems and (2) at lower concentrations: more relevant to oxidative stress than would be possible with direct measurements of $\mathrm{O}_{2} \cdot{ }^{\cdot-}\left(\varepsilon_{250}=1.9 \times 10^{3} \mathrm{M}^{-1} \mathrm{~cm}^{-1}\right)$ or $\mathrm{H}_{2} \mathrm{O}_{2}\left(\varepsilon_{240}\right.$ $\left.=43.6 \mathrm{M}^{-1} \mathrm{~cm}^{-1}\right){ }^{35,36}$ Furthermore, the $1 \mathrm{e}^{-}$reduction potential for $\mathrm{ABTS}^{--}$is lower than or comparable to the standard reduction potentials for several of the oxidizing species associated with oxidative stress in biological systems (e.g., $E^{\circ}=1.78 \mathrm{~V}$ for $\mathrm{H}_{2} \mathrm{O}_{2}, 1.6 \mathrm{~V}$ for RO', $1.0 \mathrm{~V}$ for ROO', $0.92 \mathrm{~V}$ for Cys-S', 0.70 for $\mathrm{O}_{2}$, etc.) $)^{34}$ therefore ABTS $^{--}$is a reasonable substrate for approximating biologically-relevant oxidants.

As a non-catalytic antioxidant control, Trolox (Scheme 2C) was employed given its use as a benchmark in a variety of radical degradation and antioxidant studies. ${ }^{37}$ Trolox can serve as a $1 \mathrm{e}^{-}$or $2 \mathrm{e}^{-}$reductant, whereby the first $1 \mathrm{e}^{-}$oxidation is accompanied by rapid $\mathrm{H}^{+}$loss to form a phenoxyl radical ( $\mathrm{TrO} \mathrm{O}^{*}$ ), which can then undergo a second $1 \mathrm{e}^{-}$oxidation to form a phenoxonium cation $\left(\mathrm{TrO}^{+}\right)$. However, in methanol $(\mathrm{MeOH})$ or ethanol (EtOH) solutions, these processes converge into a single $2 \mathrm{e}^{-}$oxidation. ${ }^{38}$ Subsequent hydrolysis of $\mathrm{TrO}^{+}$can then cleave the tertiary carbon-oxonium bond, which renders the $2 \mathrm{e}^{-}$ oxidation of Trolox irreversible.

Because ROS and other oxidants can cause damage to critical biomolecules, inhibiting the formation of these oxidizing species in biological systems can potentially prevent the onset of harmful pathologies. ${ }^{2}$ As a model system, we selected the oxidation of $\mathrm{ABTS}^{2-}$ to $\mathrm{ABTS}^{--}$by horseradish peroxidase (HRP) and $\mathrm{H}_{2} \mathrm{O}_{2}$ (i.e., Scheme 1-ii). ${ }^{39}$ However, before studying the ability of Ru1 to inhibit ABTS ${ }^{--}$formation, it was first necessary to explore the fundamental reactivity of Ru1 with $\mathrm{ABTS}^{--}$under controlled conditions and achieve the catalytic reduction of $\mathrm{ABTS}^{\cdot-}$ to $\mathrm{ABTS}^{2-}$ in buffered aqueous solution. 


\section{Catalytic radical reduction in EtOH}

Addition of $5 \mu \mathrm{M}$ Ru1 $\left(\mathrm{CH}_{3} \mathrm{CN}\right.$ stock) to $50 \mu \mathrm{M} \mathrm{ABTS}^{-}{ }^{-}$in EtOH caused a $100 \%$ decay in $\mathrm{ABTS}^{\circ-}$ concentration within $15 \mathrm{~min}$ (Fig. 1, red line), accompanied by the formation of $50 \mu \mathrm{M}$ ABTS $^{2-}$ (Fig. S1 $\dagger$ ), indicating the $1: 1$ conversion of $\mathrm{ABTS}^{-{ }^{-}}$to ABTS $^{2-}$ by Ru1. No ABTS ${ }^{--}$degradation occurred when $\mathrm{CH}_{3} \mathrm{CN}$ alone was added (Fig. 1, dotted green line), indicating that Ru1 was essential for the reduction of $\mathrm{ABTS}^{--}$to $\mathrm{ABTS}^{2-}$ and that $\mathrm{CH}_{3} \mathrm{CN}$ did not impact ABTS ${ }^{--}$stability. No ABTS ${ }^{--}$formation was observed in an aerobic solution containing $5 \mu \mathrm{M} \mathbf{R u 1}$ and $50 \mu \mathrm{M} \mathrm{ABTS}^{2-}$, indicating that Ru1 does not oxidize $\mathrm{ABTS}^{2-}$ to ABTS $^{--}$under these conditions. In contrast to Ru1, the addition of $5 \mu \mathrm{M}$ Trolox caused a rapid (within mixing time) $22 \%$ decrease in $\mathrm{ABTS}^{-}{ }^{-}$concentration (Fig. 1, blue line), which corresponded to the reduction of $10 \mu \mathrm{M} \mathrm{ABTS}{ }^{--}$(2 equiv. vs. Trolox) and was consistent with the ability of Trolox to serve as a non-catalytic $2 \mathrm{e}^{-}$reductant in EtOH solution. ${ }^{38}$

To assess its catalytic potential and corresponding regeneration, the reactivity of Ru1 with multiple sequential aliquots of excess $\mathrm{ABTS}^{\circ-}$ was examined. After the reduction of $50 \mu \mathrm{M}$ ABTS $^{--}$by $5 \mu \mathrm{M}$ Ru1 was complete (Fig. 2, red line), 2 additional $50 \mu \mathrm{M} \mathrm{ABTS}^{\circ-}$ aliquots were introduced $\S$ and complete ABTS ${ }^{\circ-}$ reduction was observed in each instance, indicating that Ru1 remained catalytically competent for the complete reduction of

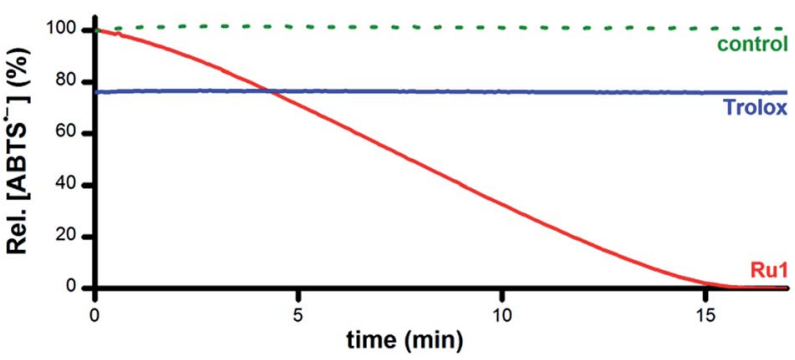

Fig. 1 Plot of relative [ABTS ${ }^{-}$] vs. time in $\mathrm{EtOH}$ following the addition of Ru1 $\left(\mathrm{CH}_{3} \mathrm{CN}\right.$ stock, red line), Trolox $\left(\mathrm{CH}_{3} \mathrm{CN}\right.$ stock, blue line), or $\mathrm{CH}_{3} \mathrm{CN}$ alone (dotted green line). Conditions: $[\text { Ru1 }]_{0}$ or $[$ Trolox] $=5 \mu \mathrm{M}$, $\left[\mathrm{ABTS}^{--}\right]_{0}=50 \mu \mathrm{M}, \mathrm{EtOH}, 25^{\circ} \mathrm{C}_{;}\left[\mathrm{ABTS}^{-}{ }^{-}\right.$] determined using absorbance measured at $750 \mathrm{~nm}$ and $\varepsilon_{750}=1.6 \times 10^{4} \mathrm{M}^{-1} \mathrm{~cm}^{-1}$ (ref. 33)

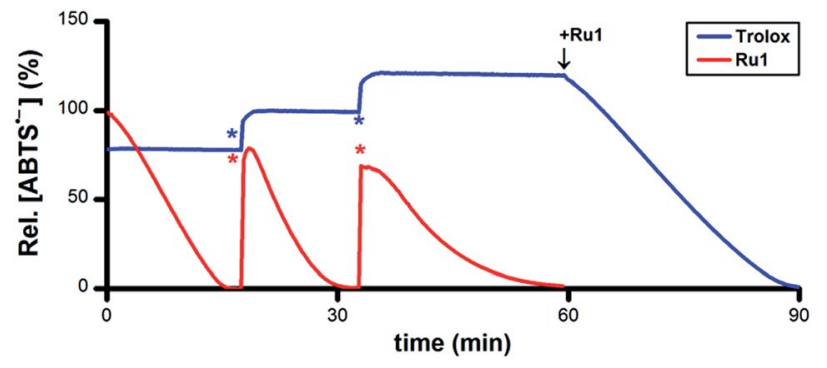

Fig. 2 Plot of relative [ABTS ${ }^{-}$] vs. time which shows the reduction of $\mathrm{ABTS}^{\cdot-}$ after adding Ru1 (red line) followed by 2 additional $50 \mu \mathrm{M}$ ABTS ${ }^{\cdot-}$ aliquots (*) and Trolox (blue line) followed by 2 additional $10 \mu \mathrm{M}$ ABTS ${ }^{*-}$ aliquots $(*)$, then $5 \mu \mathrm{M}$ Ru1. Conditions: $[\text { Ru1 }]_{0}$ or $[\text { Trolox }]_{0}=5 \mu \mathrm{M}$, [ABTS $\left.^{-}\right]_{0}=50 \mu \mathrm{M}, \mathrm{EtOH}, 25^{\circ} \mathrm{C}$ [ ABTS $^{-}$] determined using absorbance measured at $750 \mathrm{~nm}$ and $\varepsilon_{750}=1.6 \times 10^{4} \mathrm{M}^{-1} \mathrm{~cm}^{-1}$ (ref. 33).
$150 \mu \mathrm{M} \mathrm{ABTS}^{--}$(30 turnovers). Unlike Ru1, the addition of successive $10 \mu \mathrm{M}$ aliquots $\S$ of ABTS $^{--}$following the initial reduction by $5 \mu \mathrm{M}$ Trolox (Fig. 2, blue line) only caused the radical absorbance to increase by amounts equivalent to the concentration of ABTS $^{-}$added, indicating that the antioxidant capacity of Trolox had been exhausted after the reduction of only 2 equiv. of ABTS $^{*-}$. However, subsequent addition of $5 \mu \mathrm{M}$ Ru1 to the exhausted Trolox solution containing $70 \mu \mathrm{M}_{\text {ABTS }}{ }^{-}$ resulted in $100 \%$ radical reduction within $30 \mathrm{~min}$.

Addition of $5 \mu \mathrm{M}$ ascorbate $\left(\mathrm{AscH}^{-}\right)$or $5 \mu \mathrm{M}$ glutathione (GSH) to a solution of $50 \mu \mathrm{M} \mathrm{ABTS}^{{ }^{-}}$in EtOH caused the $\mathrm{ABTS}^{\circ}{ }^{-}$ concentration to decrease by $5 \%$ or $60 \%$ (Fig. S2 and $\mathrm{S} 3 \dagger$ ), values that were consistent with their ability to function as $1 \mathrm{e}^{-}$ or $6 \mathrm{e}^{-}$reductants, respectively, under these experimental conditions. ${ }^{\mathbf{4 0 - 4 2}}$ Similar to the experiments with Trolox, subsequent addition of ABTS $^{--}$only afforded increases in radical absorbance equal to the concentration of ABTS $^{*-}$ added, which likewise indicated that the antioxidant capacity of $\mathrm{AscH}^{-}$and GSH had been exhausted. Quantitative radical reduction could nonetheless be achieved via addition of $5 \mu \mathrm{M}$ Ru1 to the exhausted $\mathrm{AscH}^{-}$or GSH solutions that contained excess ABTS $^{\cdot-}$. Collectively, these data demonstrate that Ru1 can catalytically reduce $\mathrm{ABTS}^{\cdot-}$ and, because it is regenerated after each reaction cycle, that a catalytic antioxidant can offer significantly greater protection than traditional stoichiometric antioxidants, such as Trolox, $\mathrm{AscH}^{-}$and GSH.

Although $\mathrm{ABTS}^{\cdot-}$ degradation has been previously observed with other $\mathrm{Ru}$ complexes, ${ }^{\mathbf{4 3 - 4 5}} \mathbf{R u 1}$ is the first to demonstrate catalytic $\mathrm{ABTS}^{--}$reduction. It is important to note that the previous studies measured percentage of $\mathrm{ABTS}^{\cdot-}$ degradation with respect to $\mathrm{Ru}$ complex concentration, for the purpose of determining the dose dependence of radical degradation. However, the reported absorbance vs. time plots displayed significantly slower ABTS $^{-}$- degradation for the Ru complexes compared to Trolox (much like Ru1 vs. Trolox, Fig. 1) and 100\% ABTS $^{--}$degradation at multiple Ru concentrations (demonstrating dose independence). Thus, it is possible that a previously reported $\mathrm{Ru}$ complex may have degraded ABTS $^{--}$ catalytically, but its significantly slower reactivity compared to Trolox created the appearance that the percent of ABTS $^{\circ}-$ degraded was dependent on Ru complex concentration and led to the conclusion that the observed radical degradation was non-catalytic.

\section{Catalytic radical reduction in aqueous buffer}

As a catalyst for the $1 \mathrm{e}^{-}$reduction of $\mathrm{ABTS}^{{ }^{-}}$to $\mathrm{ABTS}^{2-}$, Ru1 itself cannot serve as the terminal reductant for this reaction, a role most likely played by the EtOH solvent for the experiments displayed in Fig. 1. To test this hypothesis and identify the chemical features required for terminal reductant function, it was first necessary to determine experimental conditions under which no ABTS $^{\cdot-}$ degradation occurred in the presence of Ru1 alone. Phosphate-buffered saline (PBS, pH 7.4) was selected as a suitable reaction medium because neither the solvent $\left(\mathrm{H}_{2} \mathrm{O}\right)$ nor the buffer components $\left(\mathrm{Na}_{2} \mathrm{HPO}_{4}, \mathrm{KH}_{2} \mathrm{PO}_{4}, \mathrm{NaCl}\right.$, $\mathrm{KCl}$ ) would undergo oxidation to supply the electrons necessary 


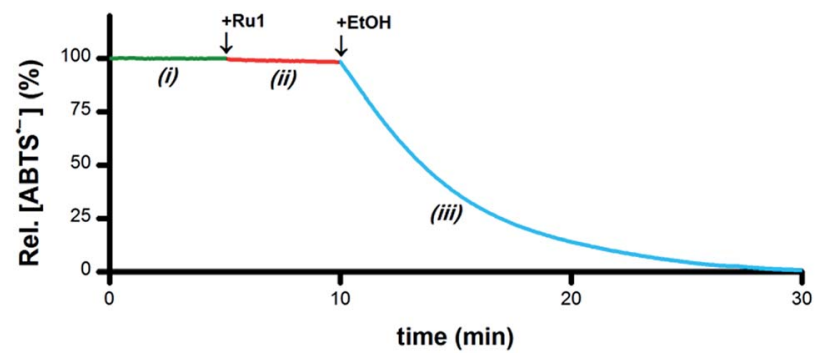

Fig. 3 Plot of relative $\left[\mathrm{ABTS}^{-}{ }^{-}\right.$] vs. time which shows the catalytic reduction of $\mathrm{ABTS}^{--}$by Ru1 in PBS. By itself, $\mathrm{ABTS}^{\cdot-}$ was stable in PBS (i, green line). Addition of Ru1 did not cause ABTS ${ }^{--}$reduction (ii, red line). Subsequent addition of EtOH caused the absorbance to decrease (iii, blue line), which indicated that $\mathrm{EtOH}$ functioned as a terminal reductant. Conditions: $[\text { Ru1 }]_{0}=5 \mu \mathrm{M},\left[\text { ABTS }^{*-}\right]_{0}=50 \mu \mathrm{M},[\mathrm{EtOH}]_{0}=50$ $\mathrm{mM}$, PBS ( $\mathrm{pH} 7.4), 25^{\circ} \mathrm{C}$; [ABTS ${ }^{--}$] determined using absorbance measured at $734 \mathrm{~nm}$ and $\varepsilon_{734}=1.5 \times 10^{4} \mathrm{M}^{-1} \mathrm{~cm}^{-1}$ (ref. 33).

for the reduction of $\mathrm{ABTS}^{--}$(i.e., Fig. 3-i). No degradation of ABTS $^{-}{ }^{-}$in PBS was observed after treatment with $5 \mu \mathrm{M}$ Ru1 (Fig. 3-ii), indicating this solution lacked a suitable terminal reductant. Subsequent addition of $50 \mathrm{mM}$ EtOH to this PBS solution containing $5 \mu \mathrm{M}$ Ru1 and $50 \mu \mathrm{M}$ ABTS $^{--}$caused the ABTS $^{-}$- concentration to decrease (Fig. 3-iii), evidence that the electrons needed for the ABTS $^{-}$- reduction observed in Fig. 1 were ultimately supplied by the EtOH solvent.

If the hypothesis that the oxidation of $\mathrm{R}_{1}-\mathrm{CHOH}-\mathrm{R}_{2}$ to $\mathrm{R}_{1}-\mathrm{C}(=\mathrm{O})-\mathrm{R}_{2}$ provides the electrons necessary for the reduction of $\mathrm{ABTS}^{\cdot-}$ to $\mathrm{ABTS}^{2-}$ is correct (i.e., Scheme 1-v), then both the $\mathrm{O}-\mathrm{H}$ and $\mathrm{C}-\mathrm{H}$ groups in a $-\mathrm{CHOH}-$ moiety will be essential for terminal reductant function. To test this hypothesis, PBS solutions containing $5 \mu \mathrm{M}$ Ru1 and $50 \mu \mathrm{M} \mathrm{ABTS}^{--}$were treated with $50 \mathrm{mM} \mathrm{MeOH}$, i-PrOH, $t$-BuOH, ethylene glycol (EG) or 1,2dimethoxyethane (DME) and the $\mathrm{ABTS}^{--}$concentration was measured. With $\mathrm{MeOH}$, i-PrOH and EG, the ABTS ${ }^{-}$concentration began to decrease immediately following addition of the alcohol, indicating that these alcohols could serve as terminal reductants (Fig. S4-S6†). In contrast, no $\mathrm{ABTS}^{\cdot-}$ reduction was

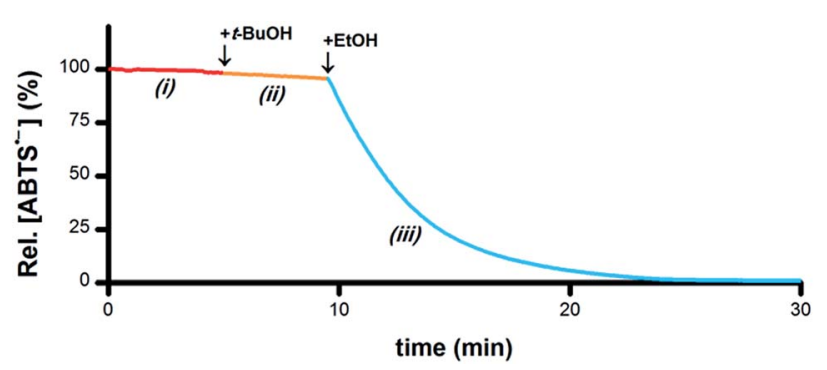

Fig. 4 Plot of relative $\left[\mathrm{ABTS}^{\cdot-}\right.$ ] vs. time which shows the catalyst is not deactivated by $t-\mathrm{BuOH}$. In a PBS solution containing only Ru1, ABTS ${ }^{\circ-}$ was stable (i, red line). Addition of $t-\mathrm{BuOH}$ did not cause any ABTS ${ }^{\cdot-}$ reduction (ii, orange line). Subsequent addition of $\mathrm{EtOH}$ resulted in ABTS $^{--}$degradation (iii, blue line), indicating that the lack of reactivity with $t-\mathrm{BuOH}$ was not due to catalyst deactivation. Conditions [Ru1 $]_{0}=$ $5 \mu \mathrm{M},\left[\mathrm{ABTS}^{\cdot-}\right]_{0}=50 \mu \mathrm{M},[t-\mathrm{BuOH}]_{0}=50 \mathrm{mM},[\mathrm{EtOH}]_{0}=50 \mathrm{mM}, \mathrm{PBS}$ (pH 7.4), $25^{\circ} \mathrm{C}$; [ABTS ${ }^{\circ}$ ] determined using absorbance measured at $734 \mathrm{~nm}$ and $\varepsilon_{734}=1.5 \times 10^{4} \mathrm{M}^{-1} \mathrm{~cm}^{-1}$ (ref. 33). observed with DME or $t$-BuOH (e.g., Fig. 4-ii). However, when the addition of $50 \mathrm{mM} t$-BuOH was followed by $50 \mathrm{mM} \mathrm{EtOH}$, $\mathrm{ABTS}^{\cdot-}$ reduction did occur (Fig. 4-iii), revealing that the lack of reactivity with $t$-BuOH was not due to catalyst deactivation but rather the inability of $t$-BuOH to serve as a terminal reductant. Collectively, these results show that the $\mathrm{C}-\mathrm{H}$ and $\mathrm{O}-\mathrm{H}$ groups of a $-\mathrm{CHOH}-$ moiety are both essential for terminal reductant function, which is consistent with the hypothesis that oxidation of $\mathrm{R}_{1}-\mathrm{CHOH}-\mathrm{R}_{2}$ to $\mathrm{R}_{1}-\mathrm{C}(=\mathrm{O})-\mathrm{R}_{2}$ provides the reducing equivalents necessary to convert ABTS ${ }^{\cdot-}$ to $\mathrm{ABTS}^{2-}$. Replacing either the $\mathrm{C}-\mathrm{H}$ group with $\mathrm{C}-\mathrm{Me}$ or the $\mathrm{O}-\mathrm{H}$ group with $\mathrm{O}-\mathrm{Me}$ precludes this oxidation and thus the ability to function as a terminal reductant, which is supported by the lack of ABTS ${ }^{\cdot-}$ reduction observed with $t$-BuOH and DME.

\section{Biologically-relevant terminal reductants}

A wide variety of biomolecules comprise - $\mathrm{CHOH}-$ groups, therefore we hypothesized that sugars, amino acids and citric acid cycle metabolites could serve as suitable terminal reductants in Ru1-catalyzed ABTS $^{--}$reduction. To test this hypothesis, PBS solutions containing $5 \mu \mathrm{M}$ Ru1 and $50 \mu \mathrm{M}$ ABTS $^{--}$ were treated with $50 \mathrm{mM}$ serine, threonine, glucose, arabinose, malic acid or lactic acid. Reduction of ABTS $^{--}$was markedly slower following the addition of the amino acids compared to the sugars, consistent with the greater number of $\mathrm{CH}-\mathrm{OH}$ groups per molecule in the latter (Fig. 5). No significant differences in reactivity were observed between serine and threonine or between glucose and arabinose.

Malic acid and lactic acid are metabolites of the citric acid cycle and each comprises a $-\mathrm{CHOH}-$ group. However, no $\mathrm{ABTS}^{\circ-}$ reduction occurred following the addition of $50 \mathrm{mM}$ malic acid or lactic acid to $5 \mu \mathrm{M}$ Ru1 and $50 \mu \mathrm{M} \mathrm{ABTS}{ }^{--}$in PBS (Fig. 6). Malate and lactate will be the predominant species in pH 7.4 PBS, and these carboxylate anions can function as chelating bidentate ligands, which could potentially disrupt the catalytic activity of Ru1. To prevent catalyst deactivation, the methyl esters of these substrates were used. Addition of $50 \mathrm{mM}$ methyl lactate (Me-lactate) or dimethyl malate $\left(\mathrm{Me}_{2}\right.$-malate) to PBS solutions containing $5 \mu \mathrm{M}$ Ru1 and $50 \mu \mathrm{M}$ ABTS $^{--}$caused the ABTS $^{--}$concentration to decrease rapidly. None of the biologically-relevant alcohols afforded ABTS ${ }^{\cdot-}$ reduction in the

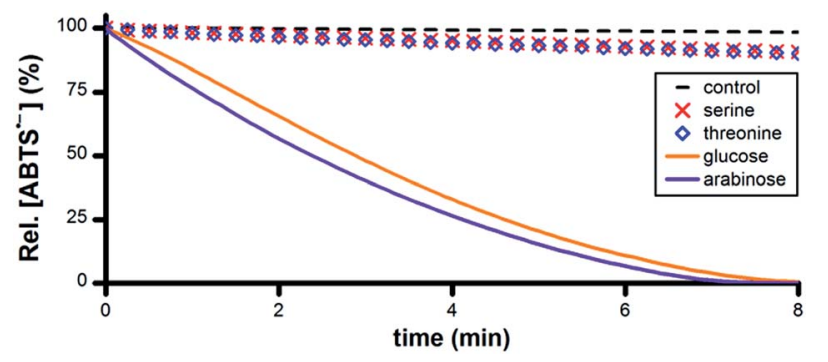

Fig. 5 Plot of relative $\left[\mathrm{ABTS}^{--}\right]$vs. time following the addition of amino acid or sugar $(t=0)$ to PBS solutions containing ABTS ${ }^{--}$and Ru1. Conditions: $[\mathrm{Ru} 1]_{0}=5 \mu \mathrm{M}$, ABTS $\left.^{\cdot-}\right]_{0}=50 \mu \mathrm{M},[\mathrm{ROH}]_{0}=50 \mathrm{mM}, \mathrm{PBS}$ (pH 7.4), $25^{\circ} \mathrm{C}_{\text {; }}\left[\mathrm{ABTS}^{--}\right.$] determined using absorbance measured at $734 \mathrm{~nm}$ and $\varepsilon_{734}=1.5 \times 10^{4} \mathrm{M}^{-1} \mathrm{~cm}^{-1}$ (ref. 33). 


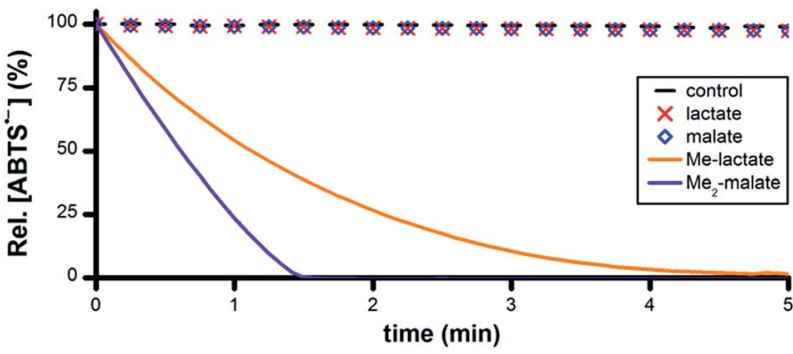

Fig. 6 Plot of relative $\left[\mathrm{ABTS}^{-}\right.$] vs. time following the addition of lactate, malate or their methyl esters $(t=0)$ to PBS solutions containing ABTS $^{\cdot-}$ and Ru1. Conditions: $[\mathrm{Ru1}]_{0}=5 \mu \mathrm{M},\left[\mathrm{ABTS}^{\cdot-}\right]_{0}=50 \mu \mathrm{M},[\mathrm{ROH}]_{0}$ $=50 \mathrm{mM}, \mathrm{PBS}(\mathrm{pH} 7.4), 25^{\circ} \mathrm{C}$ [ ABTS $^{-}$] determined using absorbance measured at $734 \mathrm{~nm}$ and $\varepsilon_{734}=1.5 \times 10^{4} \mathrm{M}^{-1} \mathrm{~cm}^{-1}$ (ref. 33).

absence of Ru1, and no oxidation of $\mathrm{ABTS}^{2-}$ to $\mathrm{ABTS}^{\cdot-}$ by Ru1 was observed under any experimental conditions in PBS.

\section{Inhibition of oxidative radical formation}

Having obtained unambiguous evidence that Ru1 catalyzes $\mathrm{ABTS}^{\cdot-}$ reduction using biologically-relevant alcohols as terminal reductants, we next sought to demonstrate that Ru1 could also inhibit radical formation. As the model system, we utilized the in situ oxidation of $\mathrm{ABTS}^{2-}$ to $\mathrm{ABTS}^{--}$by horseradish peroxidase (HRP) and $\mathrm{H}_{2} \mathrm{O}_{2}$ (i.e., Scheme 1-ii). ${ }^{39}$ Addition of $10 \mu \mathrm{M} \mathrm{H}_{2} \mathrm{O}_{2}$ to a PBS solution of $10 \mathrm{nM}$ HRP, $20 \mu \mathrm{M} \mathrm{ABTS}^{2-}, 5 \mu \mathrm{M}$ Ru1, and 50 $\mathrm{mM}$ EtOH caused the ABTS ${ }^{--}$concentration to increase immediately. The $\mathrm{ABTS}^{--}$concentration peaked at $1.0 \mu \mathrm{M}$ after 2.3 min, which then gradually declined and complete $\mathrm{ABTS}^{\cdot-}$ reduction was observed $13 \mathrm{~min}$ after the peak (Fig. 7A, red line). No ABTS ${ }^{\cdot-}$ formation occurred when $10 \mu \mathrm{M} \mathrm{H}_{2} \mathrm{O}_{2}$ was added to 5 $\mu \mathrm{M}$ Ru1 and $20 \mu \mathrm{M} \mathrm{ABTS}^{2-}$ in PBS, indicating that Ru1 did not cause any pro-oxidant reactions. Because Ru1 and Trolox were added as $30 \mu \mathrm{L}$ aliquots from $5.0 \mathrm{mM}$ stock solutions in $\mathrm{CH}_{3} \mathrm{CN}$, $10 \mu \mathrm{M} \mathrm{H}_{2} \mathrm{O}_{2}$ was added to a PBS solution containing $10 \mathrm{nM} \mathrm{HRP,}$ $20 \mu \mathrm{M} \mathrm{ABTS}^{2-}$ and $0.19 \mathrm{M} \mathrm{CH}_{3} \mathrm{CN}$ to control for the influence of this solvent. The radical absorbance immediately began to increase and reached a maximum of $17.9 \mu \mathrm{M}$ after $50 \mathrm{~min}$ (Fig. 7A, dotted green line and Fig. S7†). In contrast, the addition of $10 \mu \mathrm{M} \mathrm{H}_{2} \mathrm{O}_{2}$ to a PBS solution of $5 \mu \mathrm{M}$ Trolox, $10 \mathrm{nM}$ HRP and $20 \mu \mathrm{M} \mathrm{ABTS}^{2-}$ resulted in no change in $\mathrm{ABTS}^{--}$concentration for the first $7.6 \mathrm{~min}$, demonstrating that Trolox completely halted $\mathrm{ABTS}^{--}$formation (Fig. 7A, blue line). After $7.6 \mathrm{~min}$, however, the $\mathrm{ABTS}^{--}$concentration began to increase and reached a maximum of $9.3 \mu \mathrm{M}$ at $12 \mathrm{~min}$ after the onset of $\mathrm{ABTS}^{-{ }^{-}}$formation. Notably, the maximum $\left[\mathrm{ABTS}^{-}\right.$] observed in the presence of Trolox was $8.6 \mu \mathrm{M}$ lower than the control, which was consistent with the ability of Trolox to function as a $2 \mathrm{e}^{-}$reductant $(c f$., the $22 \%$ decrease observed with Trolox in Fig. 1A). For the control and Trolox experiments, the decline in $\mathrm{ABTS}^{--}$concentration after peaking was consistent with normal ABTS $^{--}$thermal decay.

To determine if Ru1 remained catalytically competent after the complete reduction of $\mathrm{ABTS}^{--}$formed by $10 \mathrm{nM}$ HRP and 10 $\mu \mathrm{M} \mathrm{H}_{2} \mathrm{O}_{2}$, two additional $10 \mu \mathrm{M}$ aliquots of $\mathrm{H}_{2} \mathrm{O}_{2}$ were introduced (Fig. 7B, red line). Impressively, the concentration of ABTS $^{--}$never exceeded $0.4 \mu \mathrm{M}$ and decreased back to zero in less than $16 \mathrm{~min}$ after the introduction of the second and third $\mathrm{H}_{2} \mathrm{O}_{2}$ aliquots. In contrast, addition of the second $10 \mu \mathrm{M} \mathrm{H}_{2} \mathrm{O}_{2}$ aliquot to the Trolox experiment caused the ABTS ${ }^{--}$concentration to gradually increase by $7.9 \mu \mathrm{M}$ over the course of $38 \mathrm{~min}$ (Fig. 7B, blue line), effectively resulting in complete oxidation of ABTS $^{2-}$ to $\mathrm{ABTS}^{--}$(96\% of the $17.9 \mu \mathrm{M}$ observed for control). It was therefore unsurprising that the third $10 \mu \mathrm{M} \mathrm{H}_{2} \mathrm{O}_{2}$ aliquot produced no change in radical absorbance. Subsequent addition of $50 \mathrm{mM}$ EtOH and $5 \mu \mathrm{M}$ Ru1 caused the ABTS ${ }^{--}$ concentration to decrease rapidly, affording quantitative $\mathrm{ABTS}^{--}$reduction in less than $30 \mathrm{~min}$.

To confirm that the results obtained with Ru1 arose from its ability to catalyze $\mathrm{ABTS}^{--}$reduction, rather than inhibiting HRP or another chemical reaction, two $10 \mu \mathrm{M}$ aliquots of chemically synthesized $\mathrm{ABTS}^{--}$were introduced after the ABTS ${ }^{--}$concentration had decreased to zero following the initial addition of 10 $\mu \mathrm{M} \mathrm{H}_{2} \mathrm{O}_{2}$ (Fig. 7C, red line). The first and second ABTS ${ }^{--}$aliquots produced immediate increases in $\mathrm{ABTS}^{--}$concentration corresponding to 6.3 and $6.7 \mu \mathrm{M}$, respectively, followed by rapid decreases in radical absorbance that resulted in quantitative radical reduction within $75 \mathrm{~s}$ of aliquot addition. With the Trolox experiment, however, the first and second $\mathrm{ABTS}^{--}$aliquots caused $\left[\mathrm{ABTS}^{\circ-}\right.$ ] to increase by 9.9 and $9.7 \mu \mathrm{M}$, respectively, with
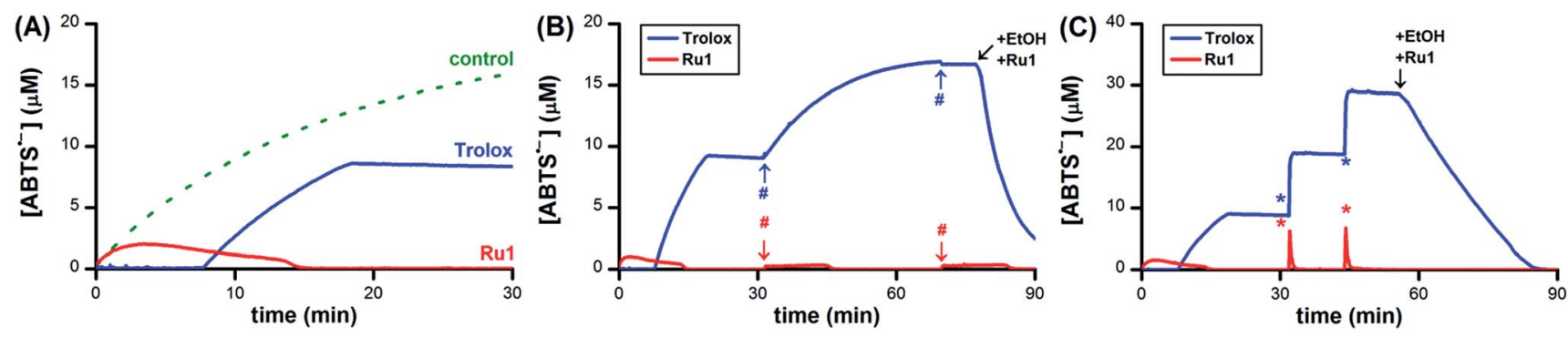

Fig. 7 (A) Plot of relative [ABTS ${ }^{-}$] vs. time which shows the in situ oxidation of $\mathrm{ABTS}^{2-}$ to $\mathrm{ABTS}^{\cdot-}$ via $\mathrm{HRP}$ and $\mathrm{H}_{2} \mathrm{O}_{2}$ in the presence of Ru1 and $\mathrm{EtOH}$ (red line), Trolox (blue line) or $0.19 \mathrm{M} \mathrm{CH}_{3} \mathrm{CN}$ as a control (dotted green line). Plot of relative [ABTS ${ }^{-}$] vs. time which shows the (B) ABTS ${ }^{\cdot-}$ formation by HRP in the presence of Ru1 and $\mathrm{EtOH}$ (red line) or Trolox (blue line) followed by two additional aliquots of $10 \mu \mathrm{M} \mathrm{H} \mathrm{H}_{2}(\#)$ or (C) two

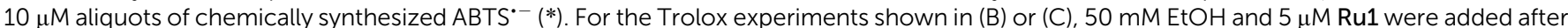
the final aliquot of $\mathrm{H}_{2} \mathrm{O}_{2}$ or $\mathrm{ABTS}^{--}$, respectively. Conditions: $[\mathrm{HRP}]_{0}=10 \mathrm{nM}[\mathrm{Ru1}]_{0}$ or $[\text { Trolox }]_{0}=5 \mu \mathrm{M},\left[\mathrm{H}_{2} \mathrm{O}_{2}\right]_{0}=10 \mu \mathrm{M},\left[\mathrm{ABTS}{ }^{2-}\right]_{0}=20 \mu \mathrm{M}$, $[\mathrm{EtOH}]_{0}=50 \mathrm{mM}, \mathrm{PBS}\left(\mathrm{pH} \mathrm{7.4)}\right.$ at $25^{\circ} \mathrm{C}_{;}\left[\mathrm{ABTS}^{-}\right.$] determined using absorbance measured at $734 \mathrm{~nm}$ and $\varepsilon_{734}=1.5 \times 10^{4} \mathrm{M}^{-1} \mathrm{~cm}^{-1}(\mathrm{ref} .33)$. 
no observable changes in radical absorbance other than thermal decay (Fig. 7C, blue line). Addition of $50 \mathrm{mM}$ EtOH and $5 \mu \mathrm{M}$ Ru1 after the second $\mathrm{ABTS}^{--}$aliquot afforded complete ABTS ${ }^{-}$ reduction within $30 \mathrm{~min}$, similar to the experiment with multiple $\mathrm{H}_{2} \mathrm{O}_{2}$ aliquots. Both $\mathrm{AscH}^{-}$and $\mathrm{GSH}$ inhibited the HRP-induced oxidation of $\mathrm{ABTS}^{2-}$, albeit for shorter periods of time and less effectively than Trolox. The introduction of additional $\mathrm{H}_{2} \mathrm{O}_{2}$ (Fig. S8 and S9†) or $\mathrm{ABTS}^{--}$aliquots (Fig. S10 and S11†) only afforded increases in $\mathrm{ABTS}^{--}$concentration that mirrored the behaviors observed for Trolox (i.e., Fig. 7B and C). Subsequent addition of $50 \mathrm{mM}$ EtOH and $5 \mu \mathrm{M}$ Ru1 to the $\mathrm{AscH}^{-}$and GSH solutions containing excess ABTS $^{--}$produced quantitative radical reduction, consistent with the Trolox experiments.

\section{Conclusions}

An organoruthenium complex (Ru1) that was previously reported to catalyze the hydrogenation of unsaturated organic substrates, using the oxidation of i-PrOH to acetone to supply the needed $\mathrm{H}_{2}$, has now been shown to also catalyze the reduction of $\mathrm{ABTS}^{--}$to $\mathrm{ABTS}^{2-}$ in buffered aqueous solution. By itself, Ru1 was unreactive towards $\mathrm{ABTS}^{--}$and the presence of a non-tertiary alcohol was essential for $\mathrm{ABTS}^{--}$reduction to occur. Replacing either the $\mathrm{C}-\mathrm{H}$ or $\mathrm{O}-\mathrm{H}$ group in a $-\mathrm{CHOH}-$ moiety with C-Me or O-Me, respectively, resulted in the loss of ABTS $^{\cdot-}$ reducing ability. Given the previously reported transfer hydrogenation activity of Ru1 and the fact that Ru1-catalyzed $\mathrm{ABTS}^{--}$reduction required a reactant comprising a $-\mathrm{CHOH}-$ moiety, we deduced that the reducing equivalents necessary for the $1 \mathrm{e}^{-}$reduction of $\mathrm{ABTS}^{--}$to $\mathrm{ABTS}^{2-}$ were supplied by the oxidation of $\mathrm{R}_{1}-\mathrm{CHOH}-\mathrm{R}_{2}$ to $\mathrm{R}_{1}-\mathrm{C}(=\mathrm{O})-\mathrm{R}_{2}$. Consistent with this deduction, a diverse array of biologically-relevant nontertiary alcohols, including amino acids, sugars and citric acid cycle metabolites, were found to be suitable terminal reductants for the reduction of ABTS ${ }^{--}$catalyzed by Ru1. Furthermore, in conjunction with an alcohol terminal reductant, Ru1 was able to inhibit the oxidation of $\mathrm{ABTS}^{2-}$ to $\mathrm{ABTS}^{--}$by $\mathrm{H}_{2} \mathrm{O}_{2}$ and horseradish peroxidase. In contrast, non-catalytic antioxidants (Trolox, ascorbate, glutathione), only offered limited protection that, once exhausted, had no impact on $\mathrm{ABTS}^{-{ }^{-}}$formation or stability. Impressively, no $\mathrm{ABTS}^{--}$formation or other prooxidant effects by Ru1 were observed under any experimental conditions. The mechanism for the catalytic reduction of ABTS $^{--}$by Ru1 and non-tertiary alcohols, along with the biological applications, will be detailed in subsequent reports.

\section{Acknowledgements}

We are grateful to A. Mangalum for preceding work and helpful insight into the synthesis of $\mathbf{2}$ and Ru1.

\section{Notes and references}

\$ In PBS, an $\mathrm{ABTS}^{--}$concentration of $6.7 \mu \mathrm{M}$ would give rise to an absorbance value of 0.1. Achieving a similar value with $\mathrm{O}_{2}{ }^{--}$or $\mathrm{H}_{2} \mathrm{O}_{2}$ would require a concentration of $53 \mu \mathrm{M}$ or $2.29 \mathrm{mM}$, respectively.
$\S$ The concentration of the successive $\mathrm{ABTS}^{{ }^{--}}$aliquots was selected based on the concentration of the initial $50 \mu \mathrm{M} \mathrm{ABTS}^{--}$that was degraded by the antioxidant. Because Ru1 degraded all of the initial $50 \mu \mathrm{M} \mathrm{ABTS}^{--}$and Trolox only degraded 10 $\mu \mathrm{M}$, the concentration of the multiple sequential aliquots added was $50 \mu \mathrm{M}$ with Ru1 and $10 \mu \mathrm{M}$ with Trolox.

1 M. P. Murphy, Biochem. J., 2009, 417, 1-13.

2 M. Valko, D. Leibfritz, J. Moncol, M. T. D. Cronin, M. Mazur and J. Telser, Int. J. Biochem. Cell Biol., 2007, 39, 44-84.

3 M. S. Cooke, M. D. Evans, M. Dizdaroglu and J. Lunec, FASEB J., 2003, 17, 1195-1214.

4 W. Maret, Antioxid. Redox Signaling, 2006, 8, 1419-1441.

5 R. Stocker and J. F. Keaney Jr, Physiol. Rev., 2004, 84, 13811478.

6 T. Fukai and M. Ushio-Fukai, Antioxid. Redox Signaling, 2011, 15, 1583-1606.

7 S. Miriyala, I. Spasojevic, A. Tovmasyan, D. Salvemini, Z. Vujaskovic, D. S. Clair and I. Batinic-Haberle, Biochim. Biophys. Acta, 2012, 1822, 794-814.

8 I. Batinic-Haberle, A. Tovmasyan, E. R. H. Roberts, Z. Vujaskovic, K. W. Leong and I. Spasojevic, Antioxid. Redox Signaling, 2014, 20, 2372-2415.

9 S. D. Amaral and B. P. Espósito, Biometals, 2008, 21, 425-432.

10 M. K. Evans, A. Tovmasyan, I. Batinic-Haberle and G. R. Devi, Free Radical Biol. Med., 2014, 68, 302-314.

11 P. Chelikani, I. Fita and P. C. Loewen, Cell. Mol. Life Sci., 2004, 61, 192-208.

12 H.-P. Hersleth, U. Ryde, P. Rydberg, C. H. Görbitz and K. K. Andersson, J. Inorg. Biochem., 2006, 100, 460-476.

13 H. N. Kirkman and G. F. Gaetani, Trends Biochem. Sci., 2007, 32, 44-50.

14 J. Vlasits, C. Jakopitsch, M. Bernroitner, M. Zamocky, P. G. Furtmüller and C. Obinger, Arch. Biochem. Biophys., 2010, 500, 74-81.

15 R. Kubota, S. Imamura, T. Shimizu, S. Asayama and H. Kawakami, ACS Med. Chem. Lett., 2014, 5, 639-643.

16 M. A. Sharpe, R. Olloson, V. C. Stewart and J. B. Clark, Biochem. J., 2002, 366, 97-107.

17 M. Itoh, K.-i. Motoda, K. Shindo, T. Kamiusuki, H. Sakiyama, N. Matsumoto and H. Ōkawa, J. Chem. Soc., Dalton Trans., 1995, 3635-3641.

18 Y. Naruta and K. Maruyama, J. Am. Chem. Soc., 1991, 113, 3595-3596.

19 R. A. Sheldon, Catal. Today, 2015, 247, 4-13.

20 B. L. Ryland and S. S. Stahl, Angew. Chem., Int. Ed., 2014, 53, 8824-8838.

21 Y. Seki, K. Oisaki and M. Kanai, Tetrahedron Lett., 2014, 55, 3738-3746.

22 C. Parmeggiani and F. Cardona, Green Chem., 2012, 14, 547564.

23 M. J. Schultz and M. S. Sigman, Tetrahedron, 2006, 62, 82278241.

24 J. J. Soldevila-Barreda, I. Romero-Canelón, A. Habtemariam and P. J. Sadler, Nat. Commun., 2015, 6, 6582.

25 Y. Fu, M. J. Romero, A. Habtemariam, M. E. Snowden, L. Song, G. J. Clarkson, B. Qamar, A. M. Pizarro, P. R. Unwin and P. J. Sadler, Chem. Sci., 2012, 3, 2485-2494. 
26 J. J. Soldevila-Barreda and P. J. Sadler, Curr. Opin. Chem. Biol., 2015, 25, 172-183.

27 P. K. Sasmal, C. N. Streu and E. Meggers, Chem. Commun., 2013, 49, 1581-1587.

28 G. Gasser and N. Metzler-Nolte, Curr. Opin. Chem. Biol., 2012, 16, 84-91.

29 A. Mangalum, C. D. McMillen and A. G. Tennyson, Inorg. Chim. Acta, 2015, 426, 29-38.

30 S. P. Fricker, E. Slade, N. A. Powell, O. J. Vaughan, G. R. Henderson, B. A. Murrer, I. L. Megson, S. K. Bisland and F. W. Flitney, Br. J. Pharmacol., 1997, 122, 1441-1449.

31 B. R. Cameron, M. C. Darkes, H. Yee, M. Olsen, S. P. Fricker, R. T. Skerlj, G. J. Bridger, N. A. Davies, M. T. Wilson, D. J. Rose and J. Zubieta, Inorg. Chem., 2003, 42, 1868-1876.

32 A. Mangalum, Y. Htet, D. A. Roe, C. D. McMillen and A. G. Tennyson, Inorg. Chim. Acta, 2015, 435, 320-326.

33 R. Re, N. Pellegrini, A. Proteggente, A. Pannala, M. Yang and C. Rice-Evans, Free Radical Biol. Med., 1999, 26, 1231-1237.

34 U. Jungwirth, C. R. Kowol, B. K. Keppler, C. G. Hartinger, W. Berger and P. Heffeter, Antioxid. Redox Signaling, 2011, 15, 1085-1127.
35 B. H. J. Bielski and A. O. Allen, J. Phys. Chem., 1977, 81, 10481050.

36 K. Yusa and K. Shikama, Biochemistry, 1987, 26, 6684-6688. 37 D. Huang, B. Ou and R. L. Prior, J. Agric. Food Chem., 2005, 53, 1841-1856.

38 M. Karbarz and J. Malyszko, Electroanalysis, 2008, 20, 18841890.

39 L. Pitulice, I. Pastor, E. Vilaseca, S. Madurga, A. Isvoran, M. Cascante and F. Mas, Biocatal. Biotransform., 2013, 2, 1-5. 40 C. Creutz, Inorg. Chem., 1981, 20, 4449-4452.

41 J. M. Pullar, M. C. M. Vissers and C. C. Winterbourn, J. Biol. Chem., 2001, 276, 22120-22125.

42 S. Enami, M. R. Hoffmann and A. J. Colussi, Chem. Res. Toxicol., 2009, 22, 35-40.

43 P. Sathyadevi, P. Krishnamoorthy, N. S. P. Bhuvanesh, P. Kalaiselvi, V. V. Padma and N. Dharmaraj, Eur. J. Med. Chem., 2012, 55, 420-431.

44 Y. Liu, X. Zhang, R. Zhang, T. Chen, Y.-S. Wong, J. Liu and W.-J. Zheng, Eur. J. Inorg. Chem., 2011, 1974-1980.

45 J. M. Alfaro, A. Prades, M. del Carmen Ramos, E. Peris, J. Ripoll-Gómez, M. Poyatos and J. S. Burgos, Zebrafish, 2010, 7, 13-21. 